\title{
Acridine Orange as a Novel Photosensitizer for Photodynamic Therapy in Glioblastoma
}

Hany Osman, MD1, Deena Elsahy, BS², M. Reza Saadatzadeh, PhD ${ }^{3,4,5}$, Karen E. Pollok, $\mathrm{PhD}^{4,5,6}$, Steven Yocom, D07, Eyas Hattab, $\mathrm{MD}^{8}$, Joseph Georges, DO, PhD ${ }^{7}$, Aaron A. CohenGadol, MD, MSc, MBA 3,9

${ }^{1}$ Massachusetts General Hospital and Harvard Medical School, Wellman Center for Photomedicine, Boston, Massachusetts

2Indiana University School of Medicine, Indianapolis, Indiana

${ }^{3}$ Hematology/Oncology, Riley Hospital for Children at Indiana University Health, Indianapolis, Indiana

${ }^{4}$ Herman B. Wells Center for Pediatric Research, Department of Pediatrics, Section of Pediatric, Indianapolis, Indiana

5Indiana University Simon Cancer Center, Indiana University School of Medicine, Indianapolis, Indiana

${ }^{6}$ Department of Pharmacology and Toxicology, Indiana University School of Medicine, Indianapolis, Indiana

${ }^{7}$ Department of Neurosurgery, Philadelphia College of Osteopathic Medicine, Philadelphia, Pennsylvania

8University of Louisville, Department of Pathology and Laboratory Medicine, Louisville, Kentucky

${ }^{9}$ Goodman Campbell Brain and Spine and Indiana University Department of Neurological Surgery, Indianapolis, Indiana

\section{E-mail addresses:}

Hany Osman: haosman@mgh.harvard.edu

Deena Elsahy: daelsahy@iupui.edu

Karen E. Pollok: kpollok@iu.edu

Steven Yocom: Yocom-Steven@cooperhealth.edu

Eyas Hattab: eyas.hattab@louisville.edu

Joseph Georges: joseph.georges@asu.edu

Aaron A. Cohen-Gadol: acohenmd@gmail.com

Key words: In vivo; microscopy; neurosurgery; glioma; oncology

Disclosure: The authors have no conflict of interest to disclose.

\section{Correspondence:}

Aaron A. Cohen-Gadol, MD, MSc

Goodman Campbell Brain and Spine

Indiana University Department of Neurological Surgery

355 W. 16th Street, Suite \#5100

Indianapolis, IN 46202

Phone: 317-362-8760 Fax: 317-924-8472

This is the author's manuscript of the article published in final edited form as:

Osman, H., Elsahy, D., Saadatzadeh, M. R., Pollok, K. E., Yocom, S., Hattab, E., ... Cohen-Gadol, A. A. (2018). 


\section{Abstract}

Object: Photodynamic therapy is an exciting treatment modality that combines the effects of a chemical agent with the physical energy from light or radiation to result in lysis of cells of interest. Acridine orange is a molecule with fluorescence properties that was demonstrated to possess photosensitizing properties. The objective of this study was to investigate the photodynamic effect of acridine orange on glioblastoma cell viability and growth.

Methods: Glioblastoma cells ( $\mathrm{n}=8000$ cells/well at 0 hours) were exposed to acridine orange followed by white unfiltered light-emitting diodes (LED) light. Cultures were exposed to either 10 or 30 minutes of light. The cell number per well was determined at 0 , 24, 48, and 72 hours after exposure.

Results: A dramatic cytocidal effect of acridine orange after exposure to as little as 10 minutes of white light was observed. There was almost complete eradication of the glioblastoma cells over a 72-hour period. Although acridine orange or light alone exhibited some effect on cell growth, it was not as pronounced as the combination of acridine orange and light.

Conclusions: This is the first study to demonstrate the photodynamic effect of acridine orange in glioblastoma cells. This data supports the need for further studies to characterize and evaluate whether this striking cytotoxic effect can be achieved in vivo. The combination of acridine orange and exposure to white unfiltered LED light may have potential future applications in management of glioblastoma. 


\section{Introduction}

Photodynamic therapy (PDT) is a treatment modality for targeting and treating disease that combines a sensitizing agent and light. The sensitizing agent accumulates in the cells of interest, and when activated by light, results in formation of cytocidal molecules. ${ }^{1}$ The utility of photodynamic therapy in the skin is perhaps one of the most studied applications given the accessibility of skin diseases. ${ }^{2,3}$ It is clinically used to treat a range of inflammatory conditions such as acne and neoplastic conditions such as actinic keratosis and squamous cell carcinoma in-situ. ${ }^{4}$ The premise of treatments with PDT relies on selective accumulation of the sensitizing agent in the tumor or inflammatory cells. ${ }^{4}$

PDT has been employed with promising results during the surgical resection of primary brain malignancies ${ }^{5}$ This application may be invaluable during resection to further optimize the extent of macroscopic and microscopic tumor resection and improve survival. ${ }^{6}$

In this study we propose to evaluate the utility of acridine orange as a photosensitizing agent for PDT of glioblastoma. The photodynamic effect of acridine orange was first noted while studying the effects of acridine on paramecia cultures. ${ }^{7}$ Von Tappenier and colleagues continued with testing photodynamic therapy using acridine orange for skin cancers. ${ }^{8}$ The effects of acridine orange as a single agent in the inhibition of tumor growth in mice were described in the late 1940s. ${ }^{9,10}$

Interest in acridine orange has since grown as a vital stain and an antitumor agent. The accentuation of toxicity of acridine orange after exposure to light was observed in early studies and has been more recently established in a series of experiments examining the photodynamic effects on cultured cells. ${ }^{11-13}$ Most recent reports focused on the utility of acridine orange topical application, although intravenous application of acridine orange has also been proposed. ${ }^{14,15}$ Direct application of acridine orange to the tumor bed followed by exposure to light has been proven as an effective adjunct to intramarginal sarcoma resections. Furthermore, direct application of acridine orange during surgery has been shown as a radiation-sensitizing agent enhancing the efficacy of postoperative radiation if applied directly to the tumor bed. ${ }^{16}$

Acridine orange has not yet been studied as a photosensitizing agent in brain tumors. In addition to being a photosensitizing agent, acridine orange is also an excellent gross contrast agent as well as an ideal contrast agent for in-vivo microscopy. ${ }^{17-20}$ Its selection for applications in neurosurgical oncology therefore serves as both a contrast agent for macroscopic and microscopic tumor identification as well as for PDT. ${ }^{21,22}$ This may therefore maximize its potential use for microscopic tumor eradication in neurosurgery, particularly for glioblastomas. 
In addition to a photosensitizing agent, a light source is necessary for the photodynamic therapeutic effect. Light source modalities range from lasers to light-emitting diodes (LED). ${ }^{23}$ Recent trends in dermatologic photodynamic therapy demonstrated the creative application of natural daylight in treatment of actinic keratosis, particularly of the scalp. ${ }^{24,25}$ The method has been shown to be as effective as conventional photodynamic therapy which uses filtered light with restricted wavelengths. ${ }^{26,27}$ For the purpose of this study, we utilized unfiltered white light from an LED with a luminous flux (LUX) similar to that of direct sunlight $\left(100,000\right.$ LUX). ${ }^{24}$

\section{Materials and Methods}

Cell Lines: To demonstrate the combined effect of acridine orange and light on the glioblastoma cell lines, 8000 cells/well of adherent U-373 MG (Sigma-Aldrich, Cat. \# 08061901) were cultured in Iscove's Modified Dulbecco's Medium (IMDM) and supplemented with $10 \mathrm{ml}, 10 \%$ fetal bovine serum. The well plates (TPP, Cat. \# 92006) were incubated for 2 days before being exposed to acridine orange and/or light.

At each time point (0-72 hours), three saline control wells with no exposure to light were counted. These wells were always kept in the dark and briefly exposed to low-intensity room light for minutes during counts. The absolute numbers per well and the average for the three wells per time point were recorded (Figure 1a and $b$ show averages). There were five different treatment regimens tested. Acridine orange alone, 10 minutes of white light alone, 30 minutes of white light alone, acridine orange plus 10 minutes of white light and acridine orange plus 30 minutes of white light. Nine wells per treatment were prepared to account for 3 measurements at 24 hours, 48 hours, and 72 hours per treatment. The measurements per well were recorded and average determined for each time point as demonstrated in Figure 1a and b.

Acridine Orange Preparation: Acridine orange was prepared by diluting acridine orange base (dye content 75\%) (Sigma-Aldrich, CAS \# 494-38-2) in saline at a final concentration of $0.001 \mathrm{mg} / \mathrm{ml}$ and used at $1 \mathrm{ml}$ per well.

Light Therapy and Intensity: After the wells were prepared, white unfiltered light from CREE XM-L T6 LED bulbs calibrated to a distance so that light incident at the level of the culture is at 100,000 LUX. The light source and intensity were selected so that no significant change in temperature was detected at 10 minutes and 30 minutes (measured using an infrared thermometer). Also, 100,000 LUX is similar to the intensity of daylight. The temperature of the cultures was measured and the light was then applied for 10 minutes and 30 minutes based on the treatment. The temperature at the end of treatment was measured and confirmed to be constant. Wells were then stored in a dark incubator 
and low-light environment was used whenever wells were removed from the incubator for counts. Exposure to light in treatments involving acridine orange was performed within 5 minutes after acridine orange was added to the cultures, and was performed only once at 0 -hour mark of the experiment.

Counting Method: Trypan blue exclusion of live cells on the Neubaure chamber hemocytometer was counted from the following formulation for each condition. Counting was carried out in three individual experiments $(n=3)$.

Total cells $/ \mathrm{ml}=\underline{\text { Total cells counted } \times \text { dilution factor } * \times 10,000}$

Number of squares counted

*In this study trypan blue was used 1:1, therefore, the dilution factor is 2 .

Briefly, at the end point of the experiment, cells were detached using $0.5 \%$ trypsin (Gibco, Life Technology, Cat. \# 25300-054) and collected in $1 \mathrm{ml}$ of IMDM+10\% fetal bovine serum (FBS). Next, $10 \mu \mathrm{l}$ of cell suspension was mixed with the same amount of trypan blue and then $10 \mu \mathrm{l}$ of it was placed under the cover slide of a hemocytometer. Finally, 5 squares of the slide were counted under a regular light microscope.

\section{Results}

The results are outlined in Figures 1a-c and Fig 2. Treatment of the cultured glioblastoma cells with acridine orange and light showed impressive cytostatic and cytocidal effects within 72 hours.

At 24 hours, there was a significant reduction in the counts from wells exposed to both acridine orange and light (PDT wells) $[p=0.003(10 \mathrm{~min})$ and $p=0.0005$ (30 min)]. There was no significant difference between 10-minute and 30-minute light exposure times for these wells. There was a mild, insignificant reduction in the number of cells in the wells with either acridine orange alone or exposure light alone at 24 hours.

At 48 hours and 72 hours, there is marked reduction in the cell counts in wells with photodynamic therapy. There was still no significant difference between the 10-minute and 30-minute light treatments. The wells exposed to either acridine orange or light alone did show a significant reduction in counts compared with control wells ( $p=<005$ at 48 hours and $\mathrm{p}=<0.0001$ at 72 hours). However, the wells treated with PDT still exhibited significant reduction in comparison with all other wells $(\mathrm{p}=<0.0001)$.

One interesting finding was that counts after 72 hours in photodynamically-treated wells were not only reduced in comparison with control wells at 72 hours, but they were lower than the starting point counts at zero hours, with counts approaching 0 (Figures 1c, 2). This demonstrates a sustained cytocidal effect that increases with time. 


\section{Discussion}

The utility of PDT to augment neurosurgical tumor excisions has been an area of interest and study for the past 50 years. ${ }^{28,29}$ Early PDT studies demonstrated the utility of hematoporphyrin as an in-vivo and in-vitro photosensitizer for the treatment of glioblastoma. ${ }^{28,29}$ Since then; multiple agents in the porphyrin family have been demonstrated as photosensitizers including; porfimer sodium (photfrin), 5-aminolevulinic acid (ALA), boronted porphyrin, hematoporphyrin (HPD), tetrakis (3-hydroxyphenyl) chlorin (mTHPC, temoporfin), photporphyrin IX and talaporfrin sodium. ${ }^{30-33}$ Photodynamic therapy using porphyrin derivatives, however, often results in prolonged systemic side effects, especially if the photosensitizing agent is injected. ${ }^{34}$ This led to development of second- and third-generation photosensitizers with more specificity toward tumor cells while sparing normal cells.

Several studies using photosensitizers demonstrate the potential that PDT provides in treating high-grade gliomas. A recent phase II multicenter randomized controlled trial showed an increase in median survival in patients receiving photodynamic therapy for high-grade gliomas in comparison with the control arm. 5

Acridine orange is a non-porphyrin molecule that is classified as an aniline dye and has different characteristics from other photosensitizers. It has a low molecular weight (265 $\mathrm{g} / \mathrm{mol}$ ) and is a hydrophobic base that is capable of quickly passing the plasma membrane, entering the cytoplasm, and accumulating in lysosomes. ${ }^{35}$ This property is essential for success of photosensitization. ${ }^{36}$ Acridine orange particularly accumulates in lysosomes with high acidity. 37,38

High-grade malignancies tend to have highly acidic extracellular conditions secondary to active cell metabolism in hypoxic conditions and therefore preferentially accumulate acridine orange. ${ }^{37,38}$ Interestingly, in addition to its accumulation in low $\mathrm{pH}$ structures, acridine orange electrostatically binds to DNA and RNA. ${ }^{39}$ The excitation spectrum (wavelength $\sim 460-500 \mathrm{~nm}$ ) of acridine orange depends on its concentration and its location/aggregation state within the cell. ${ }^{40}$ At this wavelength, light does not penetrate the tissues efficiently because of increased scattering. This means that to illicit the photodynamic effect, illumination requires direct application to the surface being treated. It also implies that the photodynamic toxicity to the underlying normal tissues is limited, possibly reducing side effects.

This phenomenon is particularly important in neurosurgical procedures and is unlike conventional photosensitizing agents which absorb light in the 600-800nm spectrum with high penetrance. Acridine orange attached to nuclear double-stranded DNA emits green light (wavelength $\sim 525 \mathrm{~nm}$ ) as it exists as a non-aggregated monomer. ${ }^{41,42}$ This form of excitation carries no toxicity and is useful as a fluorescent dye for microscopy.41-43 Orange 
light (wavelength $\sim 590 \mathrm{~nm}$ ) is emitted when acridine orange is sequestered in acidic compartments such as lysosomes. ${ }^{42}$ The latter is regarded as the photosensitizing state of this molecule. At this low $\mathrm{pH}$, acridine orange is more likely to result in oxygen radical formation and cell death.37,43,44 For this purpose, acridine orange has been used as a marker for apoptotic cells when orange fluorescence is detected as the lysosomal density and activity increases. ${ }^{45}$

Lysosomal accumulation of acridine orange also accounts for prolonged accumulation within malignant cells because it is not readily eliminated from these cells. We demonstrated this lasting effect in our experiment as the number of cultured glioblastoma cells continued to diminish 72 hours after application of the acridine orange. This prolonged accumulation in malignant cells may also account for the apparent selectivity of acridine orange PDT to malignant cells and sparing normal cells in clinical trials. ${ }^{15,37,44,46}$

Several studies documented the success of acridine orange PDT in marginal resections, particularly of sarcomas. ${ }^{14,16,47-49}$ Similar to our study, the photodynamic effect of acridine orange has been established in cultured osteosarcoma cell lines and consequently has led to its clinical use in sarcoma surgery. ${ }^{15}$ One important advantage of acridine orange is its utility as a gross and microscopic fluorescent contrast agent. ${ }^{21,22}$ The topical addition of acridine orange has been used for gross tumor delineation as well as an in- vivo microscopic fluorescence agent. ${ }^{50}$ This allows for the possibility to grossly and microscopically use fluorescence-guided resection of gliomas followed by PDT for elimination of residual tumor cells. Acridine orange also exhibits excitability following radiation, enhancing its possible utility as a radiation sensitizing agent in the adjuvant setting. ${ }^{16}$

Future considerations and studies should examine the ideal mode of photosensitizer delivery and light application as they influence the efficacy of treatment. Most photosensitizing agents are injected intravenously, with the therapeutic light applied directly to the tumor resection bed. ${ }^{51,52}$ Studies have shown that topical application of photosensitizing agents, such as in dermatologic applications, is also effective. ${ }^{34}$ Fluid-filled balloons that distribute the light to the cavity walls have been studied to evenly distribute the therapeutic light throughout. ${ }^{5}$ Recently, a few studies have also demonstrated the potential application of interstitial PDT applied via laser fibers for intra-tumor light delivery in non-resectable and recurrent glioblastomas. ${ }^{53-55}$

Reports and studies of intravenous and topical use in humans do not report immediate or long-lasting side effects, ${ }^{14,15}$ however, there currently is no substantial literature documenting the toxicity of acridine orange and further studies are needed. Mutagenic effect has been observed in bacteria ${ }^{56-58}$; however, it has not been extensively studied in humans and large animals. 


\section{Conclusions}

We have demonstrated, for the first time, the potentially impressive photodynamic effect of acridine orange on cultured glioblastoma cells. Treatment with acridine orange with as little as 10 minutes of white unfiltered light exhibited a significant cytocidal effect that increased with time. Acridine orange is a photosensitizing and contrast agent that with further optimization of delivery and light-exposure strategies may hold promise as a treatment modality for glioblastomas. Further studies validating its safety and in-vivo photodynamic effect are warranted. 


\section{References}

1. Macdonald IJ, Dougherty TJ. Basic principles of photodynamic therapy. Journal of Porphyrins and Phthalocyanines. 2001;5(02):105-129.

2. Steinbauer JM, Schreml S, Kohl EA, Karrer S, Landthaler M, Szeimies RM. Photodynamic therapy in dermatology. JDDG: Journal der Deutschen Dermatologischen Gesellschaft. 2010;8(6):454-464.

3. Kalka K, Merk H, Mukhtar H. Photodynamic therapy in dermatology. Journal of the American Academy of Dermatology. 2000;42(3):389-413.

4. Babilas P, Karrer S, Sidoroff A, Landthaler M, Szeimies RM. Photodynamic therapy in dermatology-an update. Photodermatology, photoimmunology \& photomedicine. 2005;21(3):142-149.

5. Eljamel S. Photodynamic applications in brain tumors: a comprehensive review of the literature. Photodiagnosis Photodyn Ther. 2010;7(2):76-85.

6. Lacroix M, Abi-Said D, Fourney DR, et al. A multivariate analysis of 416 patients with glioblastoma multiforme: prognosis, extent of resection, and survival. Journal of neurosurgery. 2001;95(2):190-198.

7. von Tappeiner H, Jodlbauer A. Uber die wirkung der photodynamischen (fluorescierenden) stoffe auf protozoen und enzyme. Dtsch Arch Klin Med. 1904;80:427487.

8. von Tappeiner H, Jesionek H. Therapeutische Versuche mit fluoreszierenden Stoffen. Münchner Med Wochenschr. 1903;50:2042-2044.

9. Korgaonkar KS, Sukhatankar JV. Anti-Tumour Activity of the Fluorescent Dye, Acridine Orange, on Yoshida Sarcoma (Ascites). Br J Cancer. 1963;17:471-473.

10. Lewis MR, Goland PP. In vivo staining and retardation of tumors in mice. Anat Rec. 1947;99(3):369-378.

11. Zdolsek JM. Acridine orange-mediated photodamage to cultured cells. APMIS. 1993;101(2):127-132.

12. Kusuzaki K, Minami G, Takeshita H, et al. Photodynamic inactivation with acridine orange on a multidrug-resistant mouse osteosarcoma cell line. Jpn J Cancer Res. 2000;91(4):439-445.

13. Amagasa J. Mechanisms of photodynamic inactivation of acridine orange-sensitized transfer RNA: participation of singlet oxygen and base damage leading to inactivation. $J$ Radiat Res. 1986;27(4):339-351.

14. Kusuzaki K, Murata H, Matsubara T, et al. Clinical trial of photodynamic therapy using acridine orange with/without low dose radiation as new limb salvage modality in musculoskeletal sarcomas. Anticancer Res. 2005;25(2B):1225-1235.

15. Kusuzaki K, Minami G, Takeshita H, et al. Photodynamic Inactivation with Acridine Orange on a Multidrug $\square$ resistant Mouse Osteosarcoma Cell Line. Cancer Science. 2000;91(4):439-445.

16. Hashiguchi S, Kusuzaki K, Murata H, et al. Acridine orange excited by low-dose radiation has a strong cytocidal effect on mouse osteosarcoma. Oncology. 2002;62(1):8593.

17. Kusuzaki K, Aomori K, Suginoshita T, et al. Total tumor cell elimination with minimum damage to normal tissues in musculoskeletal sarcomas following photodynamic therapy with acridine orange. Oncology. 2000;59(2):174-180. 
18. KUSUZAKI K, MURATA H, MATSUBARA T, et al. Clinical trial of photodynamic therapy using acridine orange with/without low dose radiation as new limb salvage modality in musculoskeletal sarcomas. Anticancer research. 2005;25(2B):1225-1235.

19. Kusuzaki K, Murata H, Matsubara T, et al. Clinical outcome of a novel photodynamic therapy technique using acridine orange for synovial sarcomasI. Photochemistry and photobiology. 2005;81(3):705-709.

20. Nakamura T, Kusuzaki K, Matsubara T, Matsumine A, Murata H, Uchida A. A new limb salvage surgery in cases of high $\square$ grade soft tissue sarcoma using photodynamic surgery, followed by photo $\square$ and radiodynamic therapy with acridine orange. Journal of surgical oncology. 2008;97(6):523-528.

21. Udovich JA, Besselsen DG, Gmitro AF. Assessment of acridine orange and SYTO 16 for in vivo imaging of the peritoneal tissues in mice. Journal of microscopy.

2009;234(2):124-129.

22. Tanbakuchi AA, Udovich JA, Rouse AR, Hatch KD, Gmitro AF. In vivo imaging of ovarian tissue using a novel confocal microlaparoscope. American journal of obstetrics and gynecology. 2010;202(1):90. e91-90. e99.

23. Bisland SK, Lilge L, Lin A, Rusnov R, Wilson BC. Metronomic Photodynamic Therapy as a New Paradigm for Photodynamic Therapy: Rationale and Preclinical Evaluation of Technical Feasibility for Treating Malignant Brain TumorsI. Photochemistry and photobiology. 2004;80(1):22-30.

24. Wiegell S, Wulf H, Szeimies RM, et al. Daylight photodynamic therapy for actinic keratosis: an international consensus. Journal of the European Academy of Dermatology and Venereology. 2012;26(6):673-679.

25. Batchelor R, Stables G, Stringer M. Successful treatment of scalp actinic keratoses with photodynamic therapy using ambient light. British Journal of Dermatology. 2007;156(4):779-781.

26. Rubel D, Spelman L, Murrell DF, et al. Daylight photodynamic therapy with methyl aminolevulinate cream as a convenient, similarly effective, nearly painless alternative to conventional photodynamic therapy in actinic keratosis treatment: a randomized controlled trial. British Journal of Dermatology. 2014;171(5):1164-1171.

27. Wiegell S, Hædersdal M, Philipsen P, Eriksen P, Enk C, Wulf HC. Continuous activation of PpIX by daylight is as effective as and less painful than conventional photodynamic therapy for actinic keratoses; a randomized, controlled, single $\square$ blinded study. British Journal of Dermatology. 2008;158(4):740-746.

28. Signorelli CD, Ammirati M, Tajana G. Photochemotherapy of human glioma cells in culture by hematoporphyrin and visible light (preliminary experiment). Acta Neurol (Napoli). 1978;33(2):105-112.

29. Granelli SG, Diamond I, McDonagh AF, Wilson CB, Nielsen SL. Photochemotherapy of glioma cells by visible light and hematoporphyrin. Cancer research. 1975;35(9):25672570.

30. Muller PJ, Wilson BC. Photodynamic therapy of brain tumors--a work in progress. Lasers Surg Med. 2006;38(5):384-389.

31. Eljamel MS, Goodman C, Moseley H. ALA and Photofrin fluorescence-guided resection and repetitive PDT in glioblastoma multiforme: a single centre Phase III randomised controlled trial. Lasers Med Sci. 2008;23(4):361-367. 
32. Stylli SS, Kaye AH, MacGregor L, Howes M, Rajendra P. Photodynamic therapy of high grade glioma - long term survival. J Clin Neurosci. 2005;12(4):389-398.

33. Rosenthal MA, Kavar B, Uren S, Kaye AH. Promising survival in patients with highgrade gliomas following therapy with a novel boronated porphyrin. J Clin Neurosci. 2003;10(4):425-427.

34. Wang Y, Lin Y, Zhang HG, Zhu J. A photodynamic therapy combined with topical 5aminolevulinic acid and systemic hematoporphyrin derivative is more efficient but less phototoxic for cancer. J Cancer Res Clin Oncol. 2016;142(4):813-821.

35. Canonico PG, Bird JW. The use of acridine orange as a lysosomal marker in rat skeletal muscle. J Cell Biol. 1969;43(2):367-371.

36. Ferreira GC. Heme Biochemistry. Vol 26: World Scientific; 2013.

37. Kusuzaki K, Murata H, Matsubara T, et al. Review. Acridine orange could be an innovative anticancer agent under photon energy. In Vivo. 2007;21(2):205-214.

38. Matsubara T, Kusuzaki K, Matsumine A, Shintani K, Satonaka H, Uchida A. Acridine orange used for photodynamic therapy accumulates in malignant musculoskeletal tumors depending on $\mathrm{pH}$ gradient. Anticancer Res. 2006;26(1A):187-193.

39. Palmgren MG. Acridine orange as a probe for measuring $\mathrm{pH}$ gradients across membranes: mechanism and limitations. Anal Biochem. 1991;192(2):316-321.

40. Cools AA, Janssen LH. Fluorescence response of acridine orange to changes in $\mathrm{pH}$ gradients across liposome membranes. Experientia. 1986;42(8):954-956.

41. Virant-Klun I, Tomazevic T, Meden-Vrtovec H. Sperm single-stranded DNA, detected by acridine orange staining, reduces fertilization and quality of ICSI-derived embryos. $J$ Assist Reprod Genet. 2002;19(7):319-328.

42. Han J, Burgess K. Fluorescent indicators for intracellular $\mathrm{pH}$. Chem Rev. 2010;110(5):2709-2728.

43. Falcone RD, Correa NM, Biasutti MA, Silber JJ. Acid-base and aggregation processes of acridine orange base in n-heptane/AOT/water reverse micelles. Langmuir. 2002;18(6):2039-2047.

44. Matsubara T, Kusuzaki K, Matsumine A, et al. Photodynamic therapy with acridine orange in musculoskeletal sarcomas. J Bone Joint Surg Br. 2010;92(6):760-762.

45. Kasibhatla S, Amarante-Mendes GP, Finucane D, Brunner T, Bossy-Wetzel E, Green DR. Acridine orange/ethidium bromide (AO/EB) staining to detect apoptosis. CSH Protoc. 2006;2006(3):pdb. prot4493.

46. Zoccarato F, Cavallini L, Alexandre A. The $\mathrm{pH}$-sensitive dye acridine orange as a tool to monitor exocytosis/endocytosis in synaptosomes. J Neurochem. 1999;72(2):625-633.

47. Kusuzaki K, Aomori K, Suginoshita T, et al. Total tumor cell elimination with minimum damage to normal tissues in musculoskeletal sarcomas following photodynamic therapy with acridine orange. Oncology. 2000;59(2):174-180.

48. Nakamura T, Kusuzaki K, Matsubara T, Matsumine A, Murata H, Uchida A. A new limb salvage surgery in cases of high-grade soft tissue sarcoma using photodynamic surgery, followed by photo- and radiodynamic therapy with acridine orange. J Surg Oncol. 2008;97(6):523-528.

49. Yoshida K, Kusuzaki K, Matsubara T, et al. Periosteal Ewing's sarcoma treated by photodynamic therapy with acridine orange. Oncol Rep. 2005;13(2):279-282.

50. Mirrett S. Acridine orange stain. Infect Control. 1982;3(3):250-252. 
51. Fisher CJ, Lilge L. Photodynamic therapy in the treatment of intracranial gliomas: A review of current practice and considerations for future clinical directions. J Innov Opt Health Sci. 2015;8(1):1530005.

52. Shafirstein G, Bellnier D, Oakley E, et al. Interstitial Photodynamic Therapy-A Focused Review. Cancers (Basel). 2017;9(2).

53. Beck TJ, Kreth FW, Beyer W, et al. Interstitial photodynamic therapy of nonresectable malignant glioma recurrences using 5-aminolevulinic acid induced protoporphyrin IX. Lasers Surg Med. 2007;39(5):386-393.

54. Johansson A, Faber F, Kniebuhler G, et al. Protoporphyrin IX fluorescence and photobleaching during interstitial photodynamic therapy of malignant gliomas for early treatment prognosis. Lasers Surg Med. 2013;45(4):225-234.

55. Dupont C, Betrouni N, Mordon SR, Reyns N, Vermandel M. 5-ALA photodynamic therapy in neurosurgery, towards the design of a treatment planning system: a proof of concept. IRBM. 2017;38(1):34-41.

56. Lerman LS. Acridine mutagens and DNA structure. J Cell Comp Physiol. 1964;64(S1):SUPPL 1:1-18.

57. Pietrzak M, Halicka HD, Wieczorek Z, Wieczorek J, Darzynkiewicz Z. Attenuation of acridine mutagen ICR-191--DNA interactions and DNA damage by the mutagen interceptor chlorophyllin. Biophys Chem. 2008;135(1-3):69-75.

58. Webb RB, Kubitschek HE. Mutagenic and antimutagenic effects of acridine orange in Escherichia coli. Biochem Biophys Res Commun. 1963;13(2):90-94. 


\section{Figure Legends}

Figure 1. Graphical representation of cross-sectional cultured cell counts at 24 hours (a), 48 hours (b), and 72 hours (c) demonstrating the enhanced effect of combining acridine orange and light. Wells treated with acridine orange and exposed to light showed statistical reduction in cell counts at 24 hours, 48 hours, and 72 hours. Wells with exposure to either light or acridine orange alone showed significant reduction only after 48 hours. Also, there was a significant reduction in counts in photodynamically treated wells compared with those with either acridine orange or light alone at 48 and 72 hours $(\mathrm{P}<0.005)$. Statistical analysis was performed using Tukey's multiple comparison's test. Values shown are means \pm standard deviation of three measurements. ${ }^{*} \mathrm{P}<0.005$; ${ }^{* *} \mathrm{P}<0.0001$. Abbreviations: AO, acridine orange; min, minutes.

Figure 2. Graphical representation of culture counts showing the dramatic photodynamic effect of acridine orange combined with light. Cultured cells with added acridine orange and exposed to as little as 10 minutes of light demonstrated complete, sustained, and progressive eradication of the cells within 72 hours. Acridine orange and light alone demonstrated mild reduction in the cultured cell counts in comparison with the control. Abbreviations: min, minutes, AO: acridine orange. 


\section{Hours}

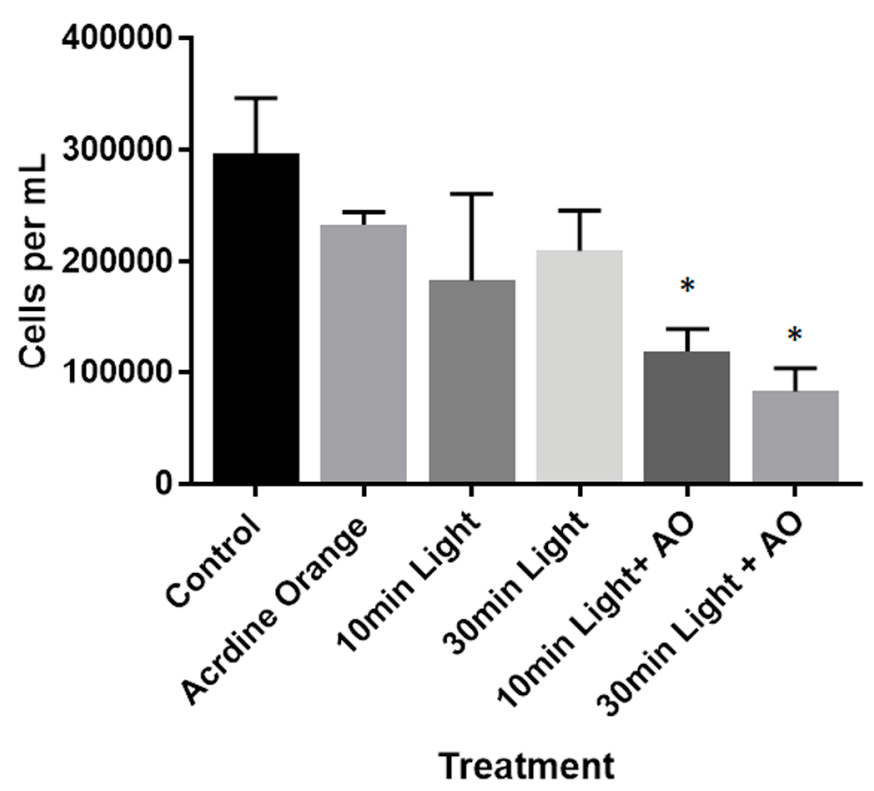




\section{Hour Data}

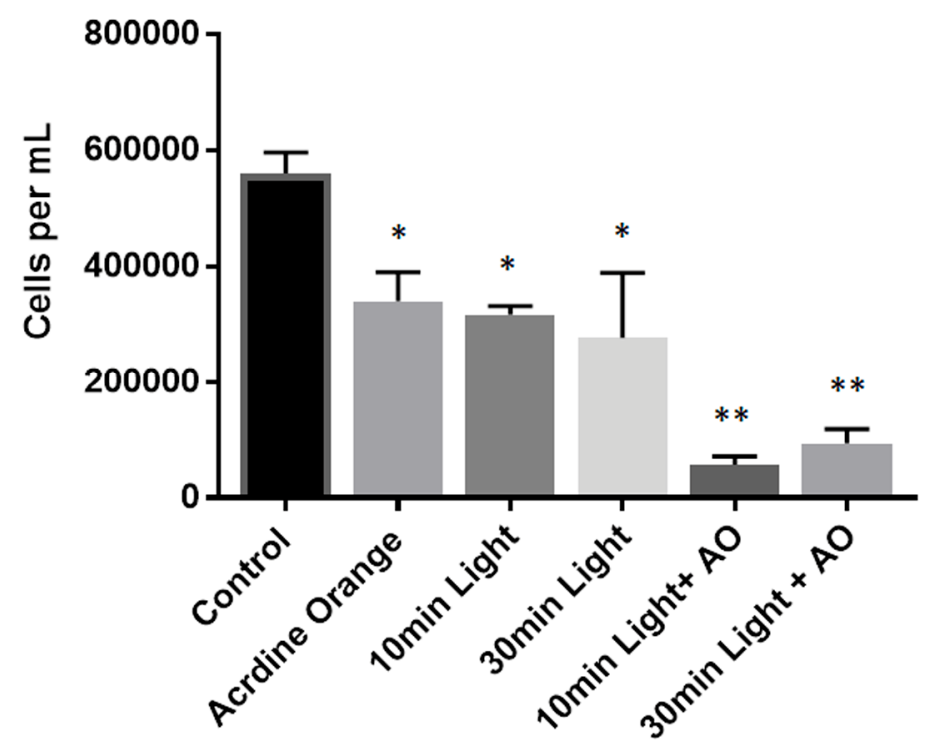




\section{2hour Data}

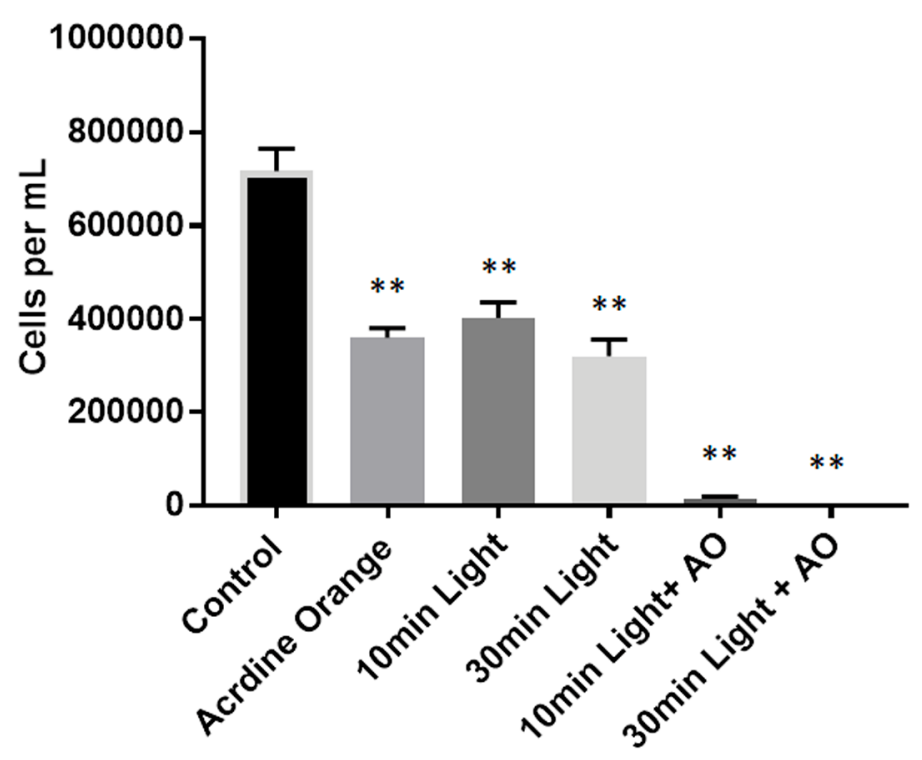




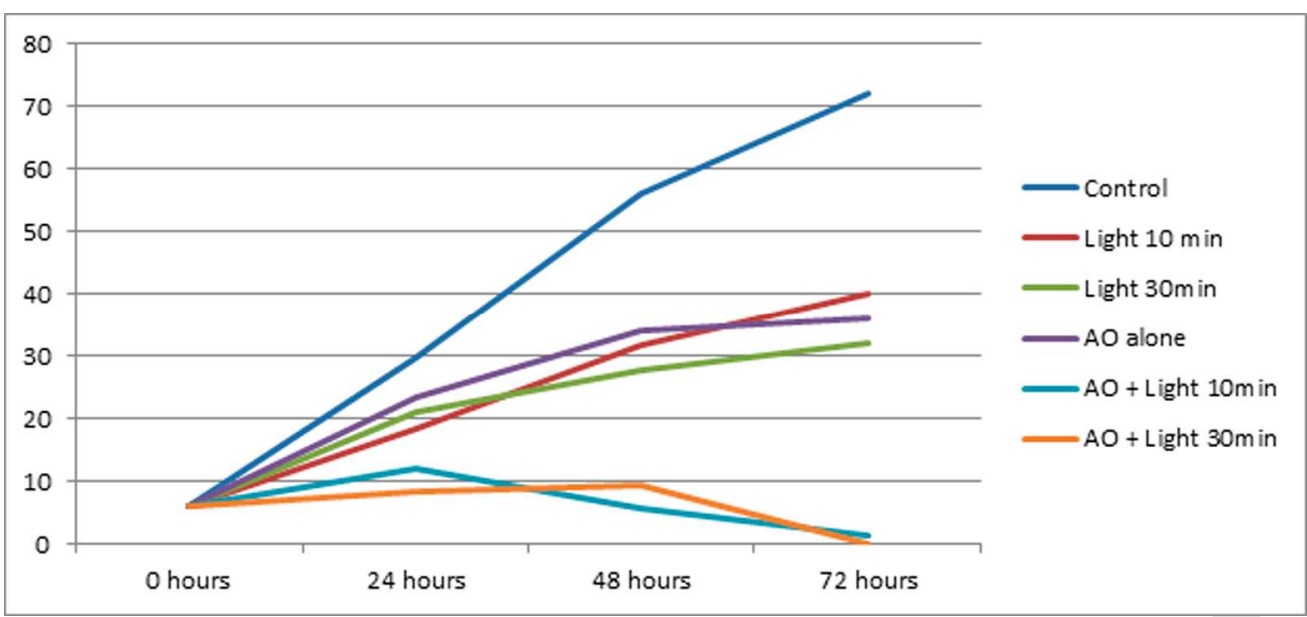




\section{Highlights}

- Acridine orange photodynamic effect is demonstrated in glioblastoma cell lines

- Treated glioblastoma cells had lower counts at 72 hours compared with starting point

- 10-minute white light is sufficient to elicit acridine orange photodynamic response

- Further optimization of acridine orange photodynamic therapy in-vivo is required 
Goodman Campbell Brain and Spine Indiana University Department of Neurological Surgery 355 West 16th Street, \#5100

Indianapolis, IN 46202

February 5, 2018

Edward C. Benzel, MD

Editor, World Neurosurgery

Cleveland Clinic

9500 Euclid Avenue / S-40

Cleveland $\mathrm{OH} 44195$

Dear Dr. Benzel:

The authors have no financial disclosures or conflict of interest in regard to this manuscript, and all ethical standards have been strictly followed.

Sincerely,

Aaron A. Cohen-Gadol, MD, MSc 


\section{Abbreviations \\ Acridine Orange as a Novel Photosensitizer for Photodynamic Therapy in Glioblastoma}

AO: acridine orange

ALA: aminolevulinic acid

FBS: fetal bovine serum

HPD: hematoporphyrin

IMDM: Iscove's Modified Dulbecco's Medium

LED: light-emitting diodes

LUX: luminous flux

PDT: photodynamic therapy 